\title{
Meta-regression analysis to predict the influence of branched-chain and large neutral amino acids on growth performance of pigs $^{1}$
}

\author{
Henrique S. Cemin, ${ }^{* 2}$ Mike D. Tokach, ${ }^{*}$ Steve S. Dritz, ${ }^{\dagger,}$ Jason C. Woodworth,* Joel M. DeRouchey,* \\ and Robert D. Goodband*
}

* Department of Animal Sciences and Industry, College of Agriculture, Kansas State University, Manhattan, KS 66506; and Department of Diagnostic Medicine/Pathobiology, College of Veterinary Medicine, Kansas State University, Manhattan, KS 66506

\begin{abstract}
A meta-analysis was conducted to evaluate the effects of branched-chain amino acids (BCAA), their interactions, and interactions with large neutral amino acids (LNAA) to develop prediction equations for growth performance of pigs. Data from 25 papers, published from 1995 to 2018, for a total of 44 trials and 210 observations were recorded in a database. Diets were reformulated using the NRC (2012) loading values to estimate nutrient concentrations. The response variables were average daily gain (ADG), average daily feed intake (ADFI), and gain-to-feed ratio (G:F). The predictor variables tested included average body weight (BW), crude protein, neutral detergent fiber, Ile:Lys, Leu:Lys, Val:Lys, BCAA:Lys, Ile:Leu, Val:Leu, Ile:Val, (Ile+Val):Leu, Trp:Lys, Leu:Trp, Ile:Trp, Val:Trp, BCAA:Trp, Met:Lys, Leu:Met, Ile:Met, Val:Met, BCAA:Met, His:Lys, Leu:His, Ile:His, Val:His, BCAA:His, Thr:Lys, Leu:Thr, Ile:Thr, Val:Thr, BCAA:Thr, (Phe+Tyr):Lys, Leu:(Phe+Tyr), Ile:(Phe+Tyr), Val:(Phe+Tyr), BCAA:(Phe+Tyr), LNAA:Lys, Leu:LNAA, Ile:LNAA, Val:LNAA, and BCAA:LNAA. Amino acids were expressed on standardized ileal digestible basis. The MIXED procedure of SAS (SAS Institute Inc., Cary, NC) was used to develop

the equations. The inverse of squared SEM was used to account for heterogeneous errors using the WEIGHT statement. Models were selected with a step-wise manual forward selection. In order to be included in the final model, predictor variables had to be statistically significant $(P<0.05)$ and provide an improvement of at least 2 points in Bayesian information criterion. The optimum equations were: ADG, $\mathrm{g}=-985.94+(15.2499 \times$ average $\mathrm{BW}(\mathrm{kg}))$ $-(0.08885 \times$ average $\mathrm{BW} \times$ average $\mathrm{BW})+(1.063 \times$ Leu:Lys $)+(20.2659 \times$ Ile:Lys $)-(0.1479 \times$ Ile:Lys $\times$ Ile:Lys $)+(9.2243 \times($ Ile + Val $): L e u)-(0.03321 \times$ (Ile+Val):Leu $\times($ Ile+Val):Leu $)-(0.4413 \times$ Ile:Trp); $\mathrm{G}: \mathrm{F}, \mathrm{g} / \mathrm{kg}=648.3-(6.2974 \times$ average $\mathrm{BW}(\mathrm{kg}))+$ $(0.02051 \times$ average $\mathrm{BW} \times$ average $\mathrm{BW})+(0.5396 \times$ Ile:Lys $)+(1.7284 \times$ Val:Lys $)-(0.00795 \times$ Val:Lys $\times$ Val:Lys $)-(1.7594 \times$ Met:Lys $) ;$ and ADFI, $\mathrm{kg}=$ predicted ADG/predicted G:F. Overall, the prediction equations suggest that increasing Leu:Lys negatively impacts ADG due to a reduction in G:F and ADFI caused by insufficient levels of other BCAA and LNAA relative to Leu. According to the model, the addition of Val, Ile, and Trp, alone or in combination, has the potential to counteract the negative effects of high dietary Leu concentrations on growth performance.
\end{abstract}

Key words: branched-chain amino acids, growth, prediction, swine

(C) The Author (s) 2019. Published by Oxford University Press on behalf of the American Society of Animal Science. All rights reserved. For permissions, please e-mail: journals.permissions@oup.com.

J. Anim. Sci. 2019.97:2505-2514

doi: $10.1093 /$ jas/skz118

\footnotetext{
${ }^{1}$ Contribution no. 19-244-J from the Kansas Agricultural Experiment Station. This work was supported by the USDA National Institute of Food and Agriculture, Hatch Funding project 1007039 .
}

${ }^{2}$ Corresponding author: hcemin@ksu.edu

Received February 28, 2019.

Accepted April 5, 2019. 


\section{INTRODUCTION}

Low crude protein (CP), amino acid (AA) fortified diets are a well-established practice to reduce diet cost and nitrogen excretion. Currently, Lys, Thr, Met, Trp, and Val are commonly used in swine diets to replace a portion of intact protein sources, such as soybean meal. After Val, Ile is probably the next limiting AA in low CP, AA-fortified diets (Figueroa et al., 2003). Of the three branched-chain amino acids (BCAA), Val and Ile are frequently limiting and thus their amount is minimized. In contrast, Leu is usually in excess in corn-based diets due to its high concentration in corn and corn by-products, such as distillers dried grains with solubles (DDGS).

The BCAA are structurally similar and share the first steps of their catabolism. Therefore, excess of a BCAA, particularly Leu, may result in increased degradation of the others (Harper et al., 1984; Brosnan and Brosnan, 2006). Moreover, BCAA and the other large neutral amino acids (LNAA), such as Trp, Tyr, Phe, Met, Thr, and His, share the same brain transporters (Pardridge, 1977; Fernstrom, 2005). Therefore, excess BCAA may decrease the AA absorption and subsequent utilization as neurotransmitter precursors that play an important role in appetite regulation. For instance, Trp is a precursor of serotonin, Tyr forms catecholamines, and His is essential for the synthesis of histamine, all of which are involved in feed intake regulation (Henry et al., 1992; Kurose and Terashima, 1999; Fernstrom, 2013).

Although data on the effects of high Leu diets on pig performance are inconsistent (Cisneros et al., 1996; Hyun et al., 2007; Morales et al., 2016), we hypothesize that practical corn-soybean meal diets supplemented with high-feed grade AA, especially with inclusion of DDGS, can potentially create imbalances and negatively impact growth performance. Therefore, the objective of this study was to evaluate prediction equations to quantify the effects of dietary BCAA, their interactions, and the potential interactions between BCAA and LNAA for nursery and growing-finishing pigs.

\section{MATERIALS AND METHODS}

\section{Database}

A literature search similar to that described by Nitikanchana et al. (2015) and Flohr et al. (2018) was conducted to directly or indirectly evaluate the effects of BCAA on growth performance. The initial screening process included trials that directly evaluated BCAA as part of the treatment structure and also those that indirectly created diet formulations with variation in one or more of the BCAA, such as Ile, Val, and Leu requirement studies. In addition, trials that assessed the inclusion of corn by-products (corn germ meal, corn gluten meal, DDGS) were considered. All data were derived exclusively from peer-reviewed publications. In order to be included in the final database, trials had to provide treatment means and SEM or SD, pigs had to have ad libitum access to feed and water, and enough diet formulation detail to recreate the diet formulation. Trials that used blood products were eliminated based on preliminary model evaluation based on model fit and residual analysis. The reason for this is not clear but could be driven by the AA profile of blood products, high in Leu and low in Ile, that results in a substantial imbalance between BCAA.

Data from each trial were recorded in a spreadsheet template. Data included average daily gain (ADG), average daily feed intake (ADFI), gain-tofeed ratio (G:F), average body weight (BW), SEM, replicates per treatment, and number of pigs per pen. For papers that reported feed efficiency as feed-to-gain ratio (F/G), the inverse proportion was calculated based on the ADG and ADFI values provided. In some cases, growth performance was reported by period. In those situations, each period was identified in the database as a trial. For trials that reported only overall performance but diet formulation by period, the average nutrient content was pooled across periods to be used with overall growth performance.

The final database contained data from 25 papers, published from 1995 to 2018, that comprised 44 trials for a total of 210 observations. Dietary treatments from each trial were reformulated using a spreadsheet-based formulator with NRC (2012) nutrient loading values for ingredients to achieve a common basis for dietary nutrient concentrations. All AA were expressed on a standardized ileal digestible basis. Dietary factors evaluated included CP, neutral detergent fiber, Ile:Lys, Leu:Lys, Val:Lys, BCAA:Lys, Ile:Leu, Val:Leu, Ile:Val, (Ile+Val):Leu, Trp:Lys, Leu:Trp, Ile:Trp, Val:Trp, BCAA:Trp, Met:Lys, Leu:Met, Ile:Met, Val:Met, BCAA:Met, His:Lys, Leu:His, Ile:His, Val:His, BCAA:His, Thr:Lys, Leu:Thr, Ile:Thr, Val:Thr, BCAA:Thr, (Phe+Tyr):Lys, Leu:(Phe+Tyr), Ile:(Phe+Tyr), Val:(Phe+Tyr), BCAA:(Phe+Tyr), LNAA:Lys, Leu:LNAA, Ile:LNAA, Val:LNAA, and BCAA:LNAA. 


\section{Statistical Analysis}

The MIXED procedure of SAS (SAS Institute Inc.) was used to develop the regression equations. The meta-regression was conducted as described by Flohr et al. (2018). Using the method of maximum likelihood, potential variables were selected by evaluating single variable equations. The statistical significance for inclusion of terms in the models was determined at $P<0.05$. The WEIGHT statement of PROC MIXED was used to account for heterogeneous errors as the inverse of squared SEM (St-Pierre, 2001). Trial was included as a random effect. The single variable model with the lowest Bayesian information criterion (BIC) was selected and additional terms were added in a step-wise manual forward selection. In order to be included in the model, a reduction of 2 points or more in BIC was required (Kass and Raftery, 1995). Linear and quadratic terms as well as interactive effects were evaluated. If the quadratic or interactive terms were statistically significant and provided an improvement in BIC, the single order variables were also included in the model. Once the model with the lowest BIC was obtained, the method of residual maximum likelihood was used to obtain the parameter estimates. These methods were used to develop regression equations to predict $\mathrm{ADG}$ and G:F. Once ADG and G:F models were obtained, predicted values were used to estimate ADFI by dividing predicted ADG by predicted G:F. The adequacy of the models was examined by evaluating studentized residuals and residuals vs. predicted values plots.

\section{RESULTS AND DISCUSSION}

A summary of the publications used in the analysis is presented in Table 1. The values describe average initial and final BW and ranges of Leu:Lys, Ile:Lys, Val:Lys, and Trp:Lys. The studies in the final database comprised an average BW range of 6.5 to $126.7 \mathrm{~kg}, 82$ to $715 \%$ Leu:Lys, 46 to $103 \%$ Ile:Lys, 38 to $124 \%$ Val:Lys, and 16 to $27 \%$ Trp:Lys. The inspection of residuals vs. predicted values relative to the line of equality (Figure 1) suggests that the predictions were precise and not biased. The

Table 1. Summary of publications used in the meta-regression to predict growth performance from branched-chained and large neutral amino acids ${ }^{1,2}$

\begin{tabular}{|c|c|c|c|c|c|c|c|}
\hline Publication & Trials & $\begin{array}{c}\text { Average } \\
\text { initial BW, kg }\end{array}$ & $\begin{array}{c}\text { Average } \\
\text { final } \mathrm{BW}, \mathrm{kg}\end{array}$ & $\begin{array}{c}\text { Range of } \\
\text { SID Leu:Lys }\end{array}$ & $\begin{array}{l}\text { Range of } \\
\text { SID Ile:Lys }\end{array}$ & $\begin{array}{c}\text { Range of } \\
\text { SID Val:Lys }\end{array}$ & $\begin{array}{c}\text { Range of } \\
\text { SID Trp:Lys }\end{array}$ \\
\hline Lewis and Nishimura (1995) & 1 & 67.0 & 80.0 & 102 & 70 & $38-93$ & 19 \\
\hline Cisneros et al. (1996) & 1 & 80.8 & 110.6 & $229-715$ & 81 & 99 & $19-24$ \\
\hline Mavromichalis et al. (2001) & 1 & 10.7 & 17.0 & $82-127$ & $50-63$ & $39-88$ & $19-20$ \\
\hline Whitney et al. (2004) & 4 & 8.2 & 16.0 & $130-176$ & $66-78$ & $71-87$ & $19-22$ \\
\hline Dean et al. (2005) & 3 & 82.3 & 114.3 & $160-251$ & $48-69$ & $64-124$ & $19-24$ \\
\hline Whitney et al. (2006) & 1 & 28.3 & 115.1 & $171-251$ & $71-89$ & $81-109$ & $20-21$ \\
\hline Hyun et al. (2007) & 1 & 73.3 & 126.7 & $204-594$ & 77 & 91 & $16-24$ \\
\hline Linneen et al. (2008) & 4 & 52.3 & 89.2 & $145-221$ & $70-87$ & $76-101$ & $20-22$ \\
\hline Weber et al. (2010) & 1 & 30.8 & 54.6 & $92-139$ & $49-64$ & $52-71$ & $19-27$ \\
\hline Xu et al. (2010) & 3 & 53.4 & 84.3 & $162-239$ & $70-73$ & 80-93 & $19-20$ \\
\hline Cromwell et al. (2011) & 3 & 61.2 & 89.8 & $176-383$ & $81-103$ & $90-133$ & $23-27$ \\
\hline Gaines et al. (2011) & 3 & 16.1 & 28.1 & $110-145$ & $58-74$ & $54-79$ & $18-22$ \\
\hline Castilha et al. (2012) & 1 & 15.4 & 30.3 & 111 & $46-67$ & 67 & 16 \\
\hline Lee et al. (2012) & 1 & 68.1 & 95.2 & $137-218$ & $63-74$ & $76-91$ & $16-20$ \\
\hline Waguespack et al. (2012) & 1 & 21.8 & 42.2 & 132 & 61 & $61-73$ & 21 \\
\hline Bergstrom et al. (2014) & 1 & 35.1 & 125.0 & $186-247$ & $71-81$ & $83-100$ & $17-19$ \\
\hline Graham et al. (2014) & 1 & 68.9 & 125.6 & $167-244$ & $70-82$ & $80-101$ & $18-19$ \\
\hline Liu et al. (2015) & 4 & 60.0 & 81.8 & $113-138$ & $52-56$ & $54-79$ & $18-23$ \\
\hline Morales et al. (2016) & 1 & 31.8 & 46.8 & $94-140$ & $57-78$ & $69-96$ & 24 \\
\hline Overholt et al. (2016) & 3 & 58.4 & 87.4 & $133-230$ & $60-78$ & $66-96$ & $17-20$ \\
\hline Clark et al. (2017) & 1 & 6.5 & 9.8 & 104 & 57 & $53-87$ & 20 \\
\hline Coble et al. (2017) & 1 & 105.7 & 125.4 & $165-209$ & $62-66$ & $75-81$ & $17-19$ \\
\hline Huepa et al. (2017) & 1 & 11.1 & 24.8 & $91-142$ & 51 & 64 & 17 \\
\hline Lazzeri et al. (2017) & 1 & 15.0 & 31.1 & 111 & $46-75$ & 68 & 17 \\
\hline Xu et al. (2018) & 1 & 8.8 & 20.1 & 113 & 53 & $60-90$ & 21 \\
\hline
\end{tabular}

${ }^{1}$ For trials that reported growth performance by period, each period was identified in the database as a trial.

${ }^{2}$ Standardized ileal digestible (SID) amino acid ranges presented are based on reformulated diets using NRC (2012) nutrient loading values. 
studentized residuals plots indicate that normality assumption was met and no evidence for outliers and heteroscedasticity was observed.

For ADG, the model with average BW as a single predictor had the lowest BIC value (2258.3) and it was a significant predictor of ADG $(P<0.01)$. Therefore, average $\mathrm{BW}$ was selected as the first predictor variable and other variables were subsequently added to the model. The step-wise inclusion of Leu:Lys (linear term; $P<0.01$, BIC = 2244.7), Ile:Lys (linear and quadratic terms; $P<0.01, \mathrm{BIC}=2238.6)$, $(\mathrm{Ile}+\mathrm{Val})$ : $\mathrm{Leu}$ (linear and quadratic terms; $P<0.01, \mathrm{BIC}=2214.6$ ), and Ile:Trp (linear term; $P<0.01$, BIC $=2208.6$ ) resulted in improvements in BIC. Other variables did not further improve BIC. Therefore, the model with average BW, Leu:Lys, Ile:Lys, (Ile+Val):Leu, and Ile:Trp was selected as the final equation with a BIC of 2208.6 (Table 2).

For the G:F model, average BW was the single predictor with the lowest BIC (2023.5). The step-wise inclusion of Val:Lys (linear and quadratic terms; $P<0.01, \mathrm{BIC}=2000.2$ ), Met:Lys (linear term; $P<0.01, \mathrm{BIC}=1990.7$ ), and Ile:Lys (linear term; $P<0.01, \mathrm{BIC}=1985.8$ ), resulted in

a)

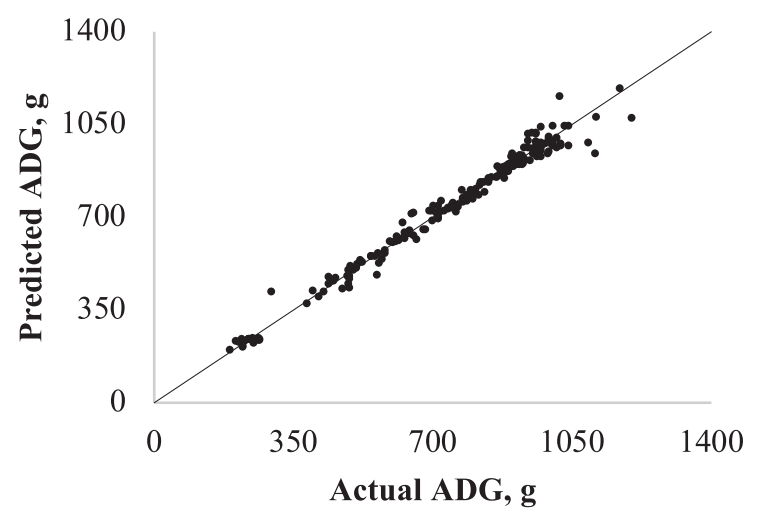

b)

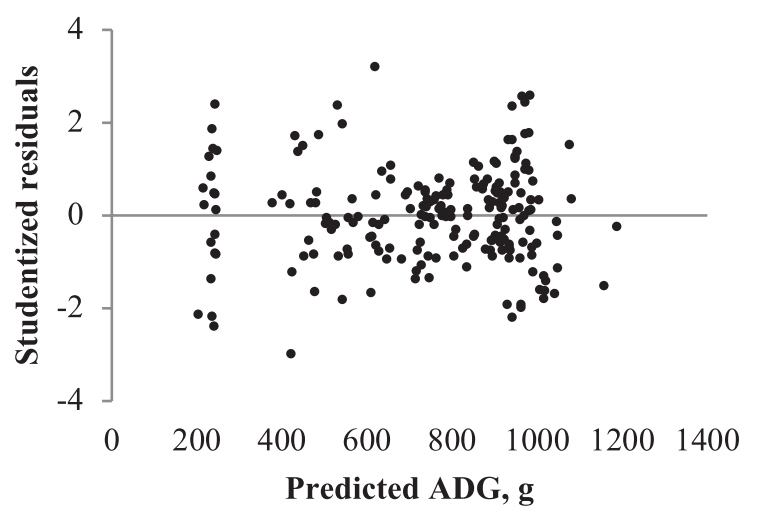

improvements in BIC. The inclusion of other variables to the model did not further improve BIC. The final equation for G:F included average BW, Ile:Lys, Val:Lys, and Met:Lys (BIC = 1985.8; Table 2).

Surprisingly, we could not develop an equation to predict ADFI with the current database. Average BW was the single predictor with the lowest BIC, but the step-wise inclusion of other predictor variables did not improve BIC. Therefore, ADFI estimates were obtained by dividing predicted ADG by predicted G:F, in a procedure similar to Flohr et al. (2018).

The equations suggest that increasing Leu:Lys ratio has a negative effect on predicted performance. This agrees with the well-described metabolism of BCAA (Harper et al., 1984; Brosnan and Brosnan, 2006). While most AA are metabolized in the liver, BCAA are transported to the skeletal muscle to be degraded. Through the action of branched-chain amino-transferase (BCAT), BCAA are reversibly converted to $\alpha$-keto acids. The $\alpha$-keto acids of Ile, Leu, and Val are $\alpha$-keto- $\beta$-methylvalerate, $\alpha$-ketoisocaproate, and $\alpha$-ketoisovalerate, respectively. In the next step, $\alpha$-keto acids are transported to the liver, where they are irreversibly

c)

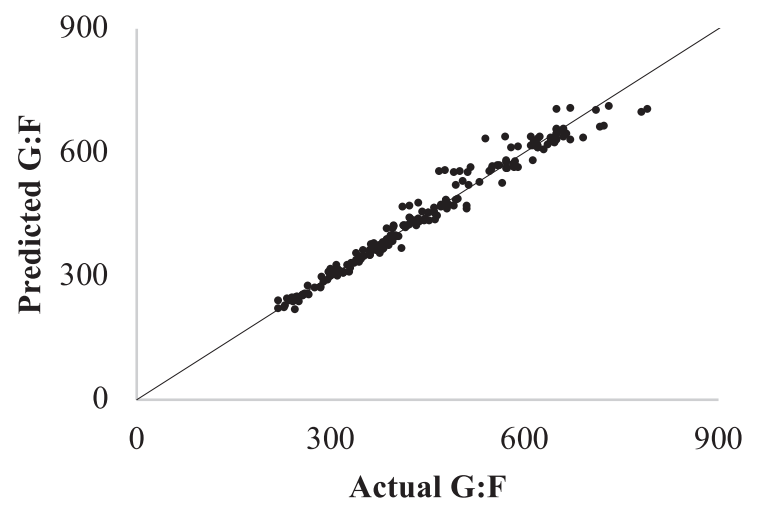

d)

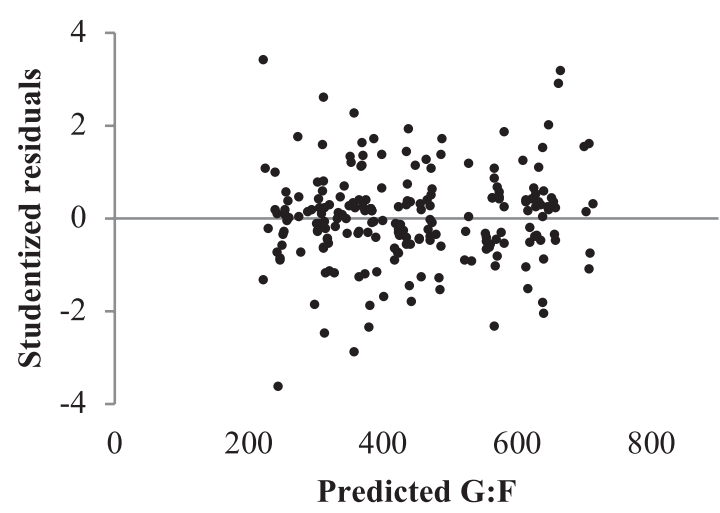

Figure 1. Plots of actual vs. predicted values relative to the line of equality and studentized residual of average daily gain (ADG) and gain-tofeed ratio (G:F). (a) and (b) Plots for ADG, and (c) and (d) plots for G:F. 
Table 2. Regression equations to predict growth performance of grow-finish pigs ${ }^{1}$

\begin{tabular}{|c|c|c|}
\hline Variable $^{2}$ & Equation $^{3}$ & $\mathrm{BIC}^{4}$ \\
\hline ADG, $g$ & 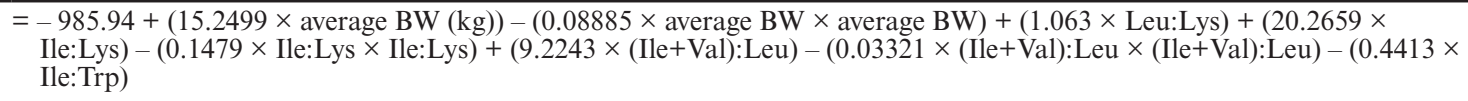 & $2,208.6$ \\
\hline $\mathrm{G}: \mathrm{F}, \mathrm{g} / \mathrm{kg}$ & $\begin{aligned}= & 648.3-(6.2974 \times \text { average BW }(\mathrm{kg}))+(0.02051 \times \text { average } \mathrm{BW} \times \text { average } \mathrm{BW})+(0.5396 \times \text { Ile:Lys })+(1.7284 \times \text { Val }: \text { Lys })- \\
& (0.00795 \times \text { Val:Lys } \times \text { Val:Lys })-(1.7594 \times \text { Met:Lys })\end{aligned}$ & $1,985.8$ \\
\hline ADFI, kg & $=$ Predicted $\mathrm{ADG} \div$ Predicted $\mathrm{G}: \mathrm{F}$ & - \\
\hline
\end{tabular}

${ }^{1}$ Model adjusted for heterogeneous errors using the inverse of squared SEM.

${ }^{2} \mathrm{ADG}=$ average daily gain. G:F = gain-to-feed ratio. ADFI = average daily feed intake.

${ }^{3}$ Average $\mathrm{BW}=$ average body weight. Amino acids ratios to lysine are expressed on standardized ileal digestible basis.

${ }^{4} \mathrm{BIC}=$ Bayesian information criterion.

decarboxylated by branched-chain $\alpha$-keto acid dehydrogenase complex (BCKD). Both enzymes BCAT and BCKD are common to all three BCAA. Stimulation of enzymatic activity by one of the BCAA will increase the catabolism of all BCAA, possibly creating antagonisms among them.

Antagonisms among BCAA are expected to be especially detrimental when the excess of a BCAA occurs while the others are marginally meeting or below the requirement. In practice, this situation commonly occurs in swine diets based on corn and/ or corn by-products supplemented with feed-grade AA. Because of the AA profile of these ingredients and the increasing use of feed-grade AA in the swine industry, it is common to have diets with high concentrations of Leu while Ile and Val are close to the requirement estimate. This becomes an important issue if we consider that the most potent stimulator of BCAT and BCKD is Leu and its $\alpha$-keto acid (Harper et al., 1984). In a recent study, Wessels et al. (2016a) fed nursery pigs with 1, 2, or 4\% dietary Leu (approximately 100, 200, and 400\% SID Leu:Lys) and observed that increasing Leu increased the activity of BCKD and reduced Ile and Val in plasma and several other tissues. This indicates that Leu stimulates not only its own catabolism but also of the other BCAA. As a consequence, Wessels et al. (2016a) observed that ADFI and ADG decreased by approximately 9 and $23 \%$ for pigs fed diets with 2 and 4\% Leu, respectively, with no impact on G:F.

Excessive Val and Ile seems to have little effect on increasing the catabolism of the other BCAA (D'Mello and Lewis, 1970), which may be partially explained by their lower affinity to BCAT and BCKD compared with Leu (Harper et al., 1984). Moreover, early research (Benton et al., 1956) showed that Leu utilization for growth was decreased by high levels of Val or Ile only when Leu was growth-limiting, which is not a common circumstance in practical swine diets. Therefore, while Leu is undoubtedly the critical BCAA in swine diets regarding antagonisms, Val and Ile seem to require more careful manipulation of AA composition to cause antagonisms (Harper et al., 1984), which seems unrealistic in practical swine diets.

Contrary to Leu, the equations indicate that Ile and Val have positive effects on predicted performance and can potentially overcome the negative effects of high concentrations of Leu. Although both AA present diminishing returns due to the quadratic terms, Ile seems to have smaller capacity to counteract the negative effects of Leu compared with Val. This is mainly driven by the quadratic term for Ile:Lys and in the negative linear term for Ile:Trp, which indicates that higher Ile relative to Trp results in decreased ADG. The ability of Val and Ile to overcome the negative impact of high levels of Leu is not a new concept. Harper et al. (1954) demonstrated that Ile partially recovered decreased growth caused by high Leu diets in rats. Later, Benton et al. (1956) demonstrated that a combination of Ile and Val was needed to fully restore growth performance in rats fed high Leu diets. Although, our meta-regression quantifies the magnitude of the effect under practical conditions of diet formulation with corn by-products and these predictions seem to agree well with the biochemical pathway data reported earlier. Recently, Millet et al. (2015) conducted a study with $10-$ to $45-\mathrm{kg}$ pigs to evaluate the effects of SID Leu (1.08 or $2.13 \%)$, Val $(0.70$ or $0.78 \%)$, Ile $(0.60$ or $0.73 \%)$, and Trp $(0.20$ or $0.25 \%)$, which resulted in ratios to Lys of approximately 97 to 192\% SID Leu:Lys, 63 to $70 \%$ SID Val:Lys, 54 to $66 \%$ SID Ile:Lys, and 18 to $22.5 \%$ SID Trp:Lys. Increasing Leu greatly decreased ADG, ADFI, and G:F and Val effectively counteracted the $A D G$ and $G: F$ reductions and partially recovered ADFI. The addition of Ile or Trp did not provide further improvements in growth performance. Thus, it seems that in diets with high Leu concentrations, more Val is needed to ensure optimal growth performance, which may 
indicate a different Val requirement depending on Leu level (Millet et al., 2015). In a study with nursery pigs, Gloaguen et al. (2011) provided diets with 60 or $70 \%$ Val:Lys and 111 or $165 \%$ Leu:Lys and observed that pigs fed diets with high Leu:Lys ratios had decreased growth performance, but the reduction was lessened with higher Val:Lys.

On the basis of our model, a similar inference can be made for Ile. However, our equations indicate that Ile alone cannot overcome the negative impact of high levels of Leu on performance and needs to be added in combination with Val and/ or Trp, which seems to agree with early research (Harper et al., 1954, 1984; Benton et al., 1956). The potential counteractive effects of Ile and Val in high Leu diets may be explained by transport competition into the brain. Hjelle et al. (1978), using an in vitro model, observed that the transport of Leu through the blood-brain barrier is inhibited by Val. This finding was confirmed by Hargreaves and Pardridge (1988), who observed that Val and, to a lesser extent, Ile, Tyr, Phe, and Trp significantly decreased the transport of Leu into the brain.

The ratio between Ile and Trp is the final component of the ADG prediction equation. As this ratio increases, due to a reduction in Trp and/ or an increase in Ile to very high levels, predicted performance is negatively impacted. The LNAA enter the brain via a shared transporter (Pardridge et al., 1977). Increasing levels of one of the LNAA raises its brain uptake and decreases the uptake of the other LNAA (Fernstrom, 2013). Carlsoon and Lindqvist (1978) observed lower Trp concentration in the brain of rats after intraperitoneal injection of Ile, Leu, or Val. Thus, it seems that Ile:Trp in the equations can be at least partially explained by the competition between Ile and Trp for brain uptake, which ultimately results in reduced serotonin activity in the brain and decreased feed intake (Henry et al., 1992). It is well described that low dietary Trp has profound effects on feed intake (Ettle and Roth, 2004; Gonçalves et al., 2015), and high Leu seems to be negatively correlated with brain Trp and serotonin (Wessels et al., 2016a, 2016b). Rogers et al. (1967) observed that in addition to Val and Ile, the inclusion of the LNAA (Trp, Phe, and Thr) was required to recover growth depression caused by a high Leu diet in rats. However, the specific interactions between Ile and Trp is not fully understood. Interestingly, the ratios of Leu or Val to Trp were not found to be significant predictors of performance in either model. However, it is important to note this only means the magnitude was not sufficiently large to be captured, it does not exclude the possibility that Leu:Trp or Val:Trp affect growth performance.

The Met:Lys ratio was a significant predictor of $\mathrm{G}: \mathrm{F}$ but not ADG. It is important to note that the trials selected for this meta-regression were not designed as Met requirement studies, thus the range of Met:Lys was fairly narrow (i.e., 27 to $56 \%$ SID Met:Lys). The NRC (2012) requirement estimate for SID Met:Lys is $29 \%$. On the basis of our equation, a decrease in G:F is observed as SID Met:Lys increases. Edmonds and Baker (1987) observed that high levels of Met result in decreased ADFI and ADG but not G:F in young pigs and Edmonds et al. (1987) observed lower ADG, ADFI, and G:F in weanling pigs fed diets with 4\% DL-Met. The relationship between Met and the BCAA is not fully understood. Surprisingly, Langer and Fuller (2000) observed that an excess of Leu or all BCAA improved $\mathrm{N}$ utilization in pigs fed Met-limiting diets. In a subsequent study, Langer et al. (2000) suggested that this may be driven by BCKD, which catabolizes BCAA keto acids but also Met keto acids. The addition of excess BCAA would affect Met catabolism by supplying alternative substrates to $\mathrm{BCKD}$, resulting in more Met available for protein synthesis. However, it is important to note that, in our model, there was no evidence for interactive terms between Met and any BCAA.

A hypothetical scenario that simulates a practical situation is shown in Table 3, where grower pig diets based on corn, soybean meal, and DDGS were formulated with low or high addition of feedgrade AA to manipulate the BCAA levels. The diet with low feed-grade AA has a greater Leu:Lys ratio compared with the diet with high inclusion of feedgrade AA. However, the predicted ADG is greater for the low than the high feed-grade AA diet because Ile:Lys and Val:Lys are also increased in the low feed-grade AA diet. The predicted ADG of the high feed-grade AA diet can be restored to the same level of the low feed-grade AA diet by supplementing Val alone or a combination of Val, Ile, and Trp.

Our equations for ADG and G:F suggest that ADFI is reduced in high Leu diets. Other research also suggests that ADFI is decreased when pigs are fed diets with high Leu or imbalanced BCAA concentrations (Harper et al., 1984; Gloaguen et al., 2011; Millet et al., 2015; Wessels et al., 2016a; Meyer et al., 2017). A possible explanation for this response is the excessive stimulation of the mammalian target for rapamycin (mTOR), a signaling pathway that stimulates protein synthesis and cell growth in the presence of adequate nutrients (Schmelze 
Table 3. Hypothetical scenario for prediction of average daily gain (ADG), gain-to-feed ratio (G:F), and average daily feed intake (ADFI) of $75 \mathrm{~kg}$ pigs based on branched-chain and large neutral amino acid concentrations ${ }^{1}$

\begin{tabular}{|c|c|c|c|c|c|}
\hline Ingredient, $\%$ & Low AA & High AA & High AA+Val & High AA+Val, Ile & High AA+Val, Ile, Trp \\
\hline Corn & 53.71 & 65.91 & 65.69 & 65.72 & 65.76 \\
\hline Soybean meal & 14.42 & 1.55 & 1.56 & 1.56 & 1.56 \\
\hline Distillers dried grains with solubles & 30.00 & 30.00 & 30.00 & 30.00 & 30.00 \\
\hline Calcium carbonate & 0.98 & 0.90 & 0.90 & 0.90 & 0.90 \\
\hline Monocalcium phosphate & - & 0.10 & 0.10 & 0.10 & 0.10 \\
\hline Salt & 0.25 & 0.25 & 0.25 & 0.25 & 0.25 \\
\hline L-Lysine $\mathrm{HCl}$ & 0.22 & 0.63 & 0.63 & 0.63 & 0.63 \\
\hline DL-Methionine & - & 0.02 & 0.02 & 0.02 & 0.02 \\
\hline L-Threonine & - & 0.16 & 0.16 & 0.16 & 0.16 \\
\hline L-Tryptophan & - & 0.07 & 0.07 & 0.07 & 0.09 \\
\hline L-Valine & - & - & 0.20 & 0.11 & 0.06 \\
\hline L-Isoleucine & - & - & - & 0.07 & 0.06 \\
\hline Vitamin-mineral premix & 0.43 & 0.43 & 0.43 & 0.43 & 0.43 \\
\hline \multicolumn{6}{|l|}{ Calculated analysis } \\
\hline Crude protein, $\%$ & 19.7 & 15.2 & 15.3 & 15.3 & 15.2 \\
\hline SID lysine & 0.82 & 0.82 & 0.82 & 0.82 & 0.82 \\
\hline SID isoleucine:lysine & 78 & 52 & 52 & 60 & 58 \\
\hline SID leucine:lysine & 211 & 173 & 173 & 173 & 173 \\
\hline SID valine:lysine & 93 & 67 & 91 & 79 & 74 \\
\hline SID tryptophan:lysine & 18.9 & 18.9 & 18.9 & 18.9 & 21.3 \\
\hline SID isoleucine:tryptophan & 413 & 275 & 275 & 319 & 274 \\
\hline SID methionine:lysine & 37 & 32 & 32 & 32 & 32 \\
\hline Predicted $\mathrm{ADG}^{2}, \mathrm{~g}$ & 911 & 852 & 911 & 911 & 911 \\
\hline$\%$ relative to low AA diet & - & 93.5 & 100 & 100 & 100 \\
\hline Predicted $\mathrm{G}: \mathrm{F}^{3}, \mathrm{~g} / \mathrm{kg}$ & 360 & 343 & 355 & 354 & 351 \\
\hline$\%$ relative to low AA diet & - & 95.3 & 98.6 & 98.3 & 97.5 \\
\hline Calculated $\mathrm{ADFI}^{4}, \mathrm{~kg}$ & 2.53 & 2.48 & 2.57 & 2.57 & 2.60 \\
\hline$\%$ relative to low AA diet & - & 98.0 & 101.6 & 101.6 & 102.7 \\
\hline
\end{tabular}

${ }^{1}$ Diets were formulated with the NRC (2012) nutrient loading values to meet or exceed the nutrient requirements.

${ }^{2} \mathrm{ADG}, \mathrm{g}=-985.94+(15.2499 \times$ average BW $(\mathrm{kg}))-(0.08885 \times$ average BW $\times$ average BW $)+(1.063 \times$ Leu:Lys $)+(20.2659 \times \mathrm{Ile}: \mathrm{Lys})-$ $(0.1479 \times$ Ile:Lys $\times$ Ile:Lys $)+(9.2243 \times($ Ile+Val $):$ Leu $)-(0.03321 \times(\mathrm{Ile}+$ Val $):$ Leu $\times(\mathrm{Ile}+$ Val $):$ Leu $)-(0.4413 \times$ Ile:Trp $)$.

${ }^{3} \mathrm{G}: \mathrm{F}, \mathrm{g} / \mathrm{kg}=648.3-(6.2974 \times$ average BW $(\mathrm{kg}))+(0.02051 \times$ average BW $\times$ average BW $)+(0.5396 \times$ Ile:Lys $)+(1.7284 \times$ Val:Lys $)-(0.00795 \times$ Val:Lys $\times$ Val:Lys $)-(1.7594 \times$ Met:Lys $)$.

${ }^{4}$ Calculated ADFI, $\mathrm{kg}=$ predicted ADG/predicted G:F.

and Hall, 2000). Leucine is a potent stimulator of mTOR and consequently plays an important role in protein synthesis (Suryawan et al., 2011). However, excessive mTOR signaling caused by high levels of Leu seems to impact growth performance through a strong inhibitory effect on feed intake (Cota et al., 2006). Interestingly, the effect on feed intake is not observed for Val (Cota et al., 2006). The available literature also supports the negative effects of increasing Leu on G:F (Gloaguen et al., 2011; Millet et al., 2015; Duan et al., 2016).

However, a few studies did not observe evidence for changes in any growth performance variable even at moderate to high Leu concentrations (Cisneros et al., 1996; Hyun et al., 2007; Morales et al., 2016). Although reasons are not well-defined, those diets were also well above the Val and Ile requirement estimates. According to our model, this could indicate that Val and Ile could be potentially counteracting the negative effect of high Leu on growth performance.

In our prediction equations, the combination of AA used to minimize the negative impact of Leu can be changed by the nutritionist to optimize feed cost depending on current AA costs. Other hypothetical scenarios with corn-soybean meal diets or different amounts of DDGS produce similar results. The implementation of prediction equations in a diet formulation is a straightforward process that would allow the nutritionist to visualize the predicted performance based on BCAA and LNAA concentrations. Field research trials are required to validate the predicted growth performance provided by the models. If proven correct, 
the prediction equations provide an important tool that allows nutritionists to formulate practical diets with high inclusion levels of feed-grade AA and overcome the negative effects of excessive Leu:Lys.

Conflict of interest statement. The authors declare that they have no conflict of interest.

\section{LITERATURE CITED}

Benton, D. A., A. E. Harper, H. E. Spivey, and C. A. Elvehjem. 1956. Leucine, isoleucine and valine relationships in the rat. Arch. Biochem. Biophys. 60:147-155. doi:10.1016/0003-9861(56)90406-4

Bergstrom, J. R., J. L. Nelssen, M. D. Tokach, S. S. Dritz, R. D. Goodband, and J. M. DeRouchey. 2014. The effects of feeder design and dietary dried distillers' grains with solubles on the performance and carcass characteristics of finishing pigs. J. Anim. Sci. 92:3591-3597. doi:10.2527/ jas.2014-7686

Brosnan, J. T., and M. E. Brosnan. 2006. Branched-chain amino acids: enzyme and substrate regulation. J. Nutr. 136:207-211. doi:10.1093/jn/136.1.207S

Castilha, L. D., P. C. Pozza, R. V. Nunes, D. B. Lazzeri, M. L. Somensi, and M. S. S. Pozza. 2012. Levels of digestible isoleucine on performance, carcass traits and organs weight of gilts (15-30 kg). Cienc. Agrotec. 36:446-453. doi:10.1590/S1413-70542012000400009

Carlsoon, A. and M. Lindqvist. 1978. Dependence of 5-HT and catecholamine synthesis on concentrations of precursor amino-acids in rat brain. Naunyn Schmiedebergs Arch. Pharmacol. 303:157-164. doi:10.1007/BF00508062

Cisneros, F., M. Ellis, D. H. Baker, R. A. Easter, and F. K. McKeith. 1996. The influence of short-term feeding of amino acid-deficient diets and high dietary leucine levels on the intramuscular fat content of pig muscle. Anim. Sci. 63:517-522. doi:10.1017/S1357729800015411

Clark, A. B., M. D. Tokach, J. M. DeRouchey, S. S. Dritz, R. D. Goodband, J. C. Woodworth, K. J. Touchette, and N. M. Bello. 2017. Modeling the effects of standardized ileal digestible valine to lysine ratio on growth performance of nursery pigs. Trans. Anim. Sci. 1:448-457. doi: $10.2527 / \operatorname{tas} 2017.0049$

Coble, K. F., J. M. DeRouchey, M. D. Tokach, S. S. Dritz, R. D. Goodband, and J. C. Woodworth. 2017. Effects of distillers dried grains with solubles and added fat fed immediately before slaughter on growth performance and carcass characteristics of finishing pigs. J. Anim. Sci. 95:270-278. doi:10.2527/jas2016.0679

Cota, D., K. Proulx, K. A. Smith, S. C. Kozma, G. Thomas, S. C. Woods, and R. J. Seeley. 2006. Hypothalamic mtor signaling regulates food intake. Science 312:927-930. doi:10.1126/science. 1124147

Cromwell, G. L., M. J. Azain, O. Adeola, S. K. Baidoo, S. D. Carter, T. D. Crenshaw, S. W. Kim, D. C. Mahan, P. S. Miller, and M. C. Shannon; North Central Coordinating Committee on Swine Nutrition. 2011. Corn distillers dried grains with solubles in diets for growing-finishing pigs: a cooperative study. J. Anim. Sci. 89:2801-2811. doi:10.2527/jas.2010-3704

Dean, D. W., L. L. Southern, B. J. Kerr, and T. D. Bidner. 2005. Isoleucine requirement of 80 - to 120-kilogram barrows fed corn-soybean meal or corn-blood cell diets. J. Anim. Sci. 83:2543-2553. doi:10.2527/2005.83112543x.
D’Mello, J. P. F., and D. Lewis. 1970. Amino acid interactions in chick nutrition. 2. Interrelationships between leucine, isoleucine and valine. Br. Poult. Sci. 16:607-615. doi:10.1080/00071667008415821

Duan, Y. H., L. M. Zeng, F. N. Li, Y. H. Li, B. E. Tan, Y. J. Ji, X. F. Kong, Y. L. Tang, Y. Z. Zhang, and Y. L. Yin. 2016. Effects of dietary branched-chain amino acid ratio on growth performance and serum amino acid pool of growing pigs. J. Anim. Sci. 2016.94:129-134. doi:10.2527/jas2015-9527

Edmonds, M. S., and D. H. Baker. 1987. Amino acid excesses for young pigs: effects of excess methionine, tryptophan, threonine or leucine. J. Anim. Sci. 64:1664-1671. doi:10.2527/jas1987.6461664x

Edmonds, M. S., H. W. Gonyou, and D. H. Baker. 1987. Effect of excess levels of methionine, tryptophan, arginine, lysine or threonine on growth and dietary choice in the pig. J. Anim. Sci. 65:179-185. doi:10.2527/jas1987.651179x

Ettle, T., and F. X. Roth. 2004. Specific dietary selection for tryptophan by the piglet. J. Anim. Sci. 82:1115-1121. doi: $10.2527 / 2004.8241115 \mathrm{x}$

Fernstrom, J. D. 2005. Branched-chain amino acids and brain function. J. Nutr. 135(6 Suppl):1539S-1546S. doi:10.1093/ jn/135.6.1539S

Fernstrom, J. D. 2013. Large neutral amino acids: dietary effects on brain neurochemistry and function. Amino Acids 45:419-430. doi:10.1007/s00726-012-1330-y

Figueroa, J. L., A. J. Lewis, P. S. Miller, R. L. Fischer, and R. M. Diedrichsen. 2003. Growth, carcass traits, and plasma amino acid concentrations of gilts fed low-protein diets supplemented with amino acids including histidine, isoleucine, and valine. J. Anim. Sci. 81:1529-1537. doi: $10.2527 / 2003.8161529 \mathrm{x}$

Flohr, J. R., S. S. Dritz, M. D. Tokach, J. C. Woodworth, J. M. DeRouchey, and R. D. Goodband. 2018. Development of equations to predict the influence of floor space on average daily gain, average daily feed intake and gain: feed ratio of finishing pigs. Animal 12:1022-1029. doi:10.1017/ S1751731117002440

Gaines, A. M., D. C. Kendall, G. L. Allee, J. L. Usry, and B. J. Kerr. 2011. Estimation of the standardized ileal digestible valine-to-lysine ratio in 13- to 32-kilogram pigs. J. Anim. Sci. 89:736-742. doi:10.2527/jas.2010-3134

Gloaguen, M., N. Le Floc'h, L. Brossard, R. Barea, Y. Primot, E. Corrent, and J. van Milgen. 2011. Response of piglets to the valine content in diet in combination with the supply of other branched-chain amino acids. Animal 5:1734-1742. doi:10.1017/S1751731111000760

Gonçalves, M. A., S. Nitikanchana, M. D. Tokach, S. S. Dritz, N. M. Bello, R. D. Goodband, K. J. Touchette, J. L. Usry, J. M. DeRouchey, and J. C. Woodworth. 2015. Effects of standardized ileal digestible tryptophan: lysine ratio on growth performance of nursery pigs. J. Anim. Sci. 93:3909-3918. doi:10.2527/jas.2015-9083

Graham, A. B., R. D. Goodband, M. D. Tokach, S. S. Dritz, J. M. DeRouchey, and S. Nitikanchana. 2014. The effects of medium-oil dried distillers grains with solubles on growth performance, carcass traits, and nutrient digestibility in growing-finishing pigs. J. Anim. Sci. 92:604-611. doi:10.2527/jas2013-6798

Hargreaves, K. M., and W. M. Pardridge. 1988. Neutral amino acid transport at the human blood-brain barrier. J. Biol. Chem. 263:19392-19397.

Harper, A. E., D. A. Benton, M. E. Winje, and C. A. Elvehjem. 1954. Leucine-isoleucine antagonism 
in the rat. Arch. Biochem. Biophys. 51:523-524. doi:10.1016/0003-9861(54)90509-3

Harper, A. E., R. H. Miller, and K. P. Block. 1984. Branchedchain amino acid metabolism. Annu. Rev. Nutr. 4:409 454. doi:10.1146/annurev.nu.04.070184.002205

Henry, Y., B. Sève, Y. Colléaux, P. Ganier, C. Saligaut, and P. Jégo. 1992. Interactive effects of dietary levels of tryptophan and protein on voluntary feed intake and growth performance in pigs, in relation to plasma free amino acids and hypothalamic serotonin. J. Anim. Sci. 70:1873-1887. doi: $10.2527 / 1992.7061873 x$

Hjelle, J. T., J. Baird-Lambert, G. Cardinale, S. Specor, and S. Udenfriend. 1978. Isolated microvessels: the bloodbrain barrier in vitro. Proc. Natl. Acad. Sci. USA. 75:4544 4548. doi:10.1073/pnas.75.9.4544

Huepa, L. M. D., M. R. Fachinello, L. A. C. Esteves, V. R. C. Paula, S. L. Ferreira, T. J. Pasquetti, L. D. Castilha, R. S. Vasconcellos, and P. C. Pozza. 2017. Leucine levels in low protein diets for pigs in the initial phase. Cienc. Agr. 38:3829-3840. doi:10.5433/1679-0359.2017v38n6p3829

Hyun, Y., J. D. Kim, M. Ellis, B. A. Peterson, D. H. Baker, and F. K. McKeith. 2007. Effect of dietary leucine and lysine levels on intramuscular fat content in finishing pigs. Can. J. Anim. Sci. 87:303-306. doi:10.4141/CJAS06042

Kass, R. E. and A. E. Raftery. 1995. Bayes factors. J. Am. Stat. Assoc. 90:773-795. doi:10.1080/01621459.1995.10476572

Kurose, Y., and Y. Terashima. 1999. Histamine regulates food intake through modulating noradrenaline release in the para-ventricular nucleus. Brain Res. 828:115-118. doi:10.1016/S0006-8993(99)01339-6

Langer, S., and M. F. Fuller. 2000. Interactions among the branched-chain amino acids and their effects on methionine utilization in growing pigs: effects on nitrogen retention and amino acid utilization. Br. J. Nutr. 83:43-48. doi:10.1017/S0007114500000076

Langer, S., P. W. Scislowski, D. S. Brown, P. Dewey, and M. F. Fuller. 2000. Interactions among the branchedchain amino acids and their effects on methionine utilization in growing pigs: effects on plasma amino- and keto-acid concentrations and branched-chain keto-acid dehydrogenase activity. Br. J. Nutr. 83:49-58. doi:10.1017/ S0007114500000088

Lazzeri, D. B., L. D. Castilha, P. B. Costa, R. V. Nunes, M. S. S. Pozza, and P. C. Pozza. 2017. Standardized ileal digestible (SID) isoleucine requirement of barrows (15- to $30-\mathrm{kg}$ ) fed low crude protein diets. Cienc. Agr. 38:32833294. doi:10.5433/1679-0359.2017v38n5p3283

Lee, J. W., F. K. McKeith, and H. H. Stein. 2012. Up to $30 \%$ corn germ may be included in diets fed to growingfinishing pigs without affecting pig growth performance, carcass composition, or pork fat quality. J. Anim. Sci. 90:4933-4942. doi:10.2527/jas.2012-5129

Lewis, A. J., and N. Nishimura. 1995. Valine requirement of the finishing pig. J. Anim. Sci. 73:2315-2318. doi: $10.2527 / 1995.7382315 \mathrm{x}$

Linneen, S. K., J. M. DeRouchey, S. S. Dritz, R. D. Goodband, M. D. Tokach, and J. L. Nelssen. 2008. Effects of dried distillers grains with solubles on growing and finishing pig performance in a commercial environment. J. Anim. Sci. 86:1579-1587. doi:10.2527/jas.2007-0486

Liu, X. T., W. F. Ma, X. F. Zeng, C. Y. Xie, P. A. Thacker, J. K. Htoo, and S. Y. Qiao. 2015. Estimation of the standardized ileal digestible valine to lysine ratio required for 25- to 120 -kilogram pigs fed low crude protein diets supplemented with crystalline amino acids. J. Anim. Sci. 93:4761-4773. doi:10.2527/jas.2015-9308

Mavromichalis, I., B. J. Kerr, T. M. Parr, D. M. Albin, V. M. Gabert, and D. H. Baker. 2001. Valine requirement of nursery pigs. J. Anim. Sci. 79:1223-1229. doi:10.2527/2001.7951223x

Meyer, F., C. Jansen van Rensburg, and R. M. Gous. 2017. The response of weaned piglets to dietary valine and leucine. Animal 11:1279-1286. doi:10.1017/S1751731116002834

Millet, S., M. Aluwé, B. Ampe, and S. De Campeneere. 2015. Interaction between amino acids on the performances of individually housed piglets. J. Anim. Physiol. Anim. Nutr. (Berl). 99:230-236. doi:10.1111/jpn.12227.

Morales, A., N. Arce, M. Cota, L. Buenabad, E. Avelar, J. K. Htoo, and M. Cervantes. 2016. Effect of dietary excess of branched-chain amino acids on performance and serum concentrations of amino acids in growing pigs. J. Anim. Physiol. Anim. Nutr. (Berl). 100:39-45. doi:10.1111/ jpn.12327

Nitikanchana, S., S. S. Dritz, M. D. Tokach, J. M. DeRouchey, R. D. Goodband, and B. J. White. 2015. Regression analysis to predict growth performance from dietary net energy in growing-finishing pigs. J. Anim. Sci. 93:2826-2839. doi:10.2527/jas.2015-9005

NRC. 2012. Nutrient requirements of swine. 11th rev. ed. National Academy Press, Washington, DC.

Overholt, M. F., J. E. Lowell, E. K. Arkfeld, I. M. Grossman, H. H. Stein, A. C. Dilger, and D. D. Boler. 2016. Effects of pelleting diets without or with distillers' dried grains with solubles on growth performance, carcass characteristics, and gastrointestinal weights of growing-finishing barrows and gilts. J. Anim. Sci. 94:2172-2183. doi:10.2527/ jas2015-0202

Pardridge, W. M. 1977. Kinetics of competitive inhibition of neutral amino acid transport across the blood-brain barrier. J. Neurochem. 28:103-108. doi:10.1111/j.1471-4159.1977. tb07714.X

Rogers, Q. R., R. I. Tannous, and A. E. Harper. 1967. Effects of excess leucine on growth and food selection. J. Nutr. 91:561-572. doi:10.1093/jn/91.4.561

Schmelze, T., and M. N. Hall. 2000. TOR, a central controller of cell growth. Cell 2:253-262. doi:10.1016/ S0092-8674(00)00117-3

St-Pierre, N. R. 2001. Integrating quantitative findings from multiple studies using mixed model methodology. J. Dairy Sci. 84:741-755. doi:10.3168/jds.S0022-0302(01)74530-4

Suryawan, A., R. A. Orellana, M. L. Fiorotto, and T. A. Davis. 2011. Triennial growth symposium: leucine acts as a nutrient signal to stimulate protein synthesis in neonatal pigs. J. Anim. Sci. 89:2004-2016. doi:10.2527/jas.2010-3400

Waguespack, A. M., T. D. Bidner, R. L. Payne, and L. L. Southern. 2012. Valine and isoleucine requirement of 20- to 45-kilogram pigs. J. Anim. Sci. 90:2276-2284. doi:10.2527/jas.2011-4454

Weber, T. E., S. L. Trabue, C. J. Ziemer, and B. J. Kerr. 2010. Evaluation of elevated dietary corn fiber from corn germ meal in growing female pigs. J. Anim. Sci. 88:192-201. doi:10.2527/jas.2009-1896

Wessels, A. G., H. Kluge, F. Hirche, A. Kiowski, A. Schutkowski, E. Corrent, J. Bartelt, B. König, and G. I. Stangl. 2016a. High leucine diets stimulate cerebral branched-chain amino acid degradation and 
modify serotonin and ketone body concentrations in a pig model. PLoS One 11:e0150376. doi:10.1371/journal. pone. 0150376

Wessels, A. G., H. Kluge, F. Hirche, A. Kiowski, J. Bartelt, E. Corrent, and G. I. Stangl. 2016b. High leucine intake reduces the concentration of hypothalamic serotonin in piglets. J. Anim. Sci. 94:26-29. doi:10.2527/jas2015-9728

Whitney, M. H., and G. C. Shurson. 2004. Growth performance of nursery pigs fed diets containing increasing levels of corn distiller's dried grains with solubles originating from a modern midwestern ethanol plant. J. Anim. Sci. 82:122-128. doi: $10.2527 / 2004.821122 x$

Whitney, M. H., G. C. Shurson, L. J. Johnston, D. M. Wulf, and B. C. Shanks. 2006. Growth performance and carcass characteristics of grower-finisher pigs fed high-quality corn distillers dried grain with solubles originating from a modern midwestern ethanol plant. J. Anim. Sci. 84:33563363. doi:10.2527/jas.2006-099

Xu, G., S. K. Baidoo, L. J. Johnston, D. Bibus, J. E. Cannon, and G. C. Shurson. 2010. Effects of feeding diets containing increasing content of corn distillers dried grains with solubles to grower-finisher pigs on growth performance, carcass composition, and pork fat quality. J. Anim. Sci. 88:1398-1410. doi:10.2527/jas.2008-1404

Xu, Y. T., X. K. Ma, C. L. Wang, M. F. Yuan, and X. S. Piao. 2018. Effects of dietary valine:lysine ratio on the performance, amino acid composition of tissues and mrna expression of genes involved in branched-chain amino acid metabolism of weaned piglets. Asian-Australas. J. Anim. Sci. 31:106-115. doi:10.5713/ajas.17.0148 